\title{
Peroxy radical isomerization in the oxidation of isoprene $\dagger$
}

\author{
John D. Crounse, ${ }^{* a}$ Fabien Paulot, ${ }^{b}$ Henrik G. Kjaergaard ${ }^{c}$ and Paul O. Wennberg ${ }^{b d}$ \\ Received 26th April 2011, Accepted 8th June 2011 \\ DOI: $10.1039 / \mathrm{c} 1 \mathrm{cp} 21330 \mathrm{j}$
}

We report experimental evidence for the formation of $\mathrm{C}_{5}$-hydroperoxyaldehydes (HPALDs) from 1,6-H-shift isomerizations in peroxy radicals formed from the hydroxyl radical (OH) oxidation of 2-methyl-1,3-butadiene (isoprene). At $295 \mathrm{~K}$, the isomerization rate of isoprene peroxy radicals $\left(\mathrm{ISO}_{2}^{\circ}\right)$ relative to the rate of reaction of $\mathrm{ISO}_{2}^{-}+\mathrm{HO}_{2}$ is $\frac{k_{\text {isom }}^{295}}{k_{\mathrm{ISO}_{2}^{-1}+\mathrm{HO}_{2}}^{\text {95 }}}=$ $(1.2 \pm 0.6) \times 10^{8} \mathrm{~mol} \mathrm{~cm}^{-3}$, or $k_{\text {isom }}^{295} \simeq 0.002 \mathrm{~s}^{-1}$. The temperature dependence of this rate was determined through experiments conducted at 295, 310 and $318 \mathrm{~K}$ and is well described by

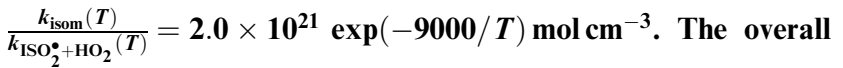
uncertainty in the isomerization rate (relative to $\boldsymbol{k}_{\mathrm{ISO}_{2}+\mathrm{HO}_{2}}$ ) is estimated to be $50 \%$. Peroxy radicals from the oxidation of the fully deuterated isoprene analog isomerize at a rate $\sim 15$ times slower than non-deuterated isoprene. The fraction of isoprene peroxy radicals reacting by $1,6-\mathrm{H}$-shift isomerization is estimated to be $8-11 \%$ globally, with values up to $20 \%$ in tropical regions.

Approximately $500 \mathrm{Tg}$ of isoprene $\left(\mathrm{C}_{5} \mathrm{H}_{8}\right)$ originating primarily from plants is released to Earth's atmosphere each year. ${ }^{1}$ The oxidation of isoprene in the atmosphere is primarily initiated by reaction with hydroxyl radicals $(\mathrm{OH})$. The bulk of this reaction proceeds through addition of the $\mathrm{OH}$ to one of the two external olefinic carbon atoms. In the presence of oxygen, six different peroxy radicals (collectively $\mathrm{ISO}_{2}^{\bullet}$ ) are formed from reaction with $\mathrm{O}_{2}(\mathrm{R} 1)$.

$$
\text { isoprene }+\mathrm{OH} \stackrel{\mathrm{O}_{2}}{\longrightarrow} \mathrm{ISO}_{2}^{\bullet}
$$

In nearly all chemical mechanisms used to describe atmospheric photochemistry, the subsequent fate of $\mathrm{ISO}_{2}^{\bullet}$ is

${ }^{a}$ Division of Chemistry and Chemical Engineering,

California Institute of Technology, Pasadena, CA 91125, USA.

E-mail: crounjd@caltech.edu; Fax: + 1626585 1917;

Tel: + 16263958551

${ }^{b}$ Division of Engineering and Applied Science,

California Institute of Technology, Pasadena, CA 91125, USA

${ }^{c}$ Department of Chemistry, DK-2100 Copenhagen Ø,

University of Copenhagen, Copenhagen, Denmark

${ }^{d}$ Division of Geological and Planetary Sciences,

California Institute of Technology, Pasadena, CA 91125, USA

$\dagger$ Electronic supplementary information (ESI) available: Calibration details including dipole moments and polarizabilities for ISOPOOH and HPALD isomers and short discussion and figure regarding the 1,5-H-shift isomerization rates. See DOI: $10.1039 / \mathrm{c} 1 \mathrm{cp} 21330 \mathrm{j}$ determined by reaction with either $\mathrm{NO}$ ( $\mathrm{R} 2 \mathrm{a}$ and $\mathrm{R} 2 \mathrm{~b}$ ) or $\mathrm{HO}_{2}$ (R3).

$$
\begin{aligned}
& \mathrm{ISO}_{2}^{\bullet}+\mathrm{NO} \stackrel{k_{\mathrm{ISO}_{2}^{+}+\mathrm{NO}} \times(1-\mathrm{NY})}{\longrightarrow} \mathrm{ISO}^{\bullet}+\mathrm{NO}_{2} \\
& \mathrm{ISO}_{2}^{\bullet}+\mathrm{NO} \stackrel{k_{\mathrm{ISO}_{2}^{\bullet+\mathrm{NO}}} \times \mathrm{NY}}{\longrightarrow} \mathrm{ISONO}_{2},
\end{aligned}
$$

where NY $=$ nitrate yield

$$
\mathrm{ISO}_{2}^{\bullet}+\mathrm{HO}_{2} \stackrel{k_{\mathrm{ISO}_{2}^{\bullet}+\mathrm{HO}_{2}}}{\longrightarrow} \mathrm{ISOPOOH}+\mathrm{O}_{2}
$$

This representation is consistent with a wealth of laboratory studies of the reactivity of peroxy radicals. Such studies have typically been performed with sufficient concentrations of $\mathrm{NO}$ or $\mathrm{HO}_{2}$ that the lifetimes of the peroxy radicals are very short-often less than $0.1 \mathrm{~s}$. For vast regions of the atmosphere (including most of the tropics), however, the peroxy radicals are estimated to live for 10's of seconds before finding a reactive partner in either $\mathrm{NO}$ or $\mathrm{HO}_{2}$ (e.g., for observed $\mathrm{NO}$ and $\mathrm{HO}_{2}$ levels over Amazonia, ${ }^{2} \mathrm{ISO}_{2}^{\bullet}$ lifetime with respect to $\mathrm{R} 2 \mathrm{a}-\mathrm{R} 3$ is calculated to be $30-60 \mathrm{~s}$ ).

A number of recent analyses have cast doubt on the traditional representation of peroxy radical chemistry (R2a-R3). In particular, motivated by the inability to explain measured concentrations of $\mathrm{OH}$ in regions with elevated levels of biogenically-derived hydrocarbons, ${ }^{2-6}$ investigators have hypothesized that the peroxy radicals of the dominant VOC, isoprene, may not follow the traditional reactive pathways. Most recently, Peeters et al. ${ }^{7}$ and da Silva et al. ${ }^{8}$ have estimated from quantum mechanical calculations that intramolecular hydrogen transfer reactions of the isoprene peroxy radicals (R4) may diminish the impact of isoprene oxidation on $\mathrm{HO}_{x}$ concentrations.

$$
\mathrm{ISO}_{2}^{\bullet} \stackrel{k_{\text {isom }}}{\longrightarrow} \mathrm{HO}_{x}+\operatorname{carbonyl}(\mathrm{s})
$$

Here, we report product yields in the oxidation of isoprene and its fully deuterated analog by $\mathrm{OH}$ in the presence of $\mathrm{NO}$ and $\mathrm{HO}_{2}$ concentrations similar to those encountered in the environment. We report temperature dependent formation rates for unsaturated $\mathrm{C}_{5}$-hydroperoxyaldehydes (HPALDs) ${ }^{7}$ generated through 1,6-H-shift isomerization of two of the six peroxy radical isomers, Z-1-OH-4-OO (R5) and Z-4-OH-1-OO (R6). We assess the extent to which these intramolecular hydrogen 
transfer reactions occur in the atmosphere using the GEOS-Chem chemical transport model.
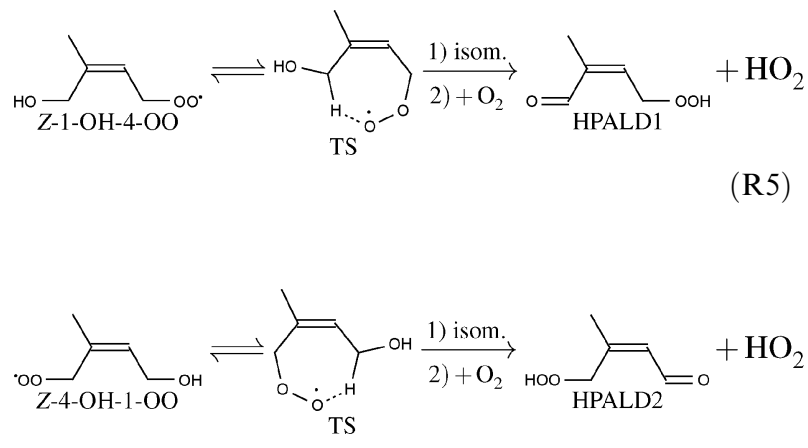

\section{Experiment}

Experiments were conducted within a $\sim 1 \mathrm{~m}^{3}$ bag composed of a fluorinated ethylene propylene copolymer (Teflon-FEP, DuPont). The bag was enclosed in a chamber that is painted black on the inside and equipped with ultra-violet (UV) lights (Sylvania F40/350BL) mounted to one wall. Photolysis of $\mathrm{CH}_{3} \mathrm{ONO}$ provided the primary $\mathrm{HO}_{x}$ source as described in R7-R8. ${ }^{9}$ In order to achieve the slow chemistry required to study the $\mathrm{RO}_{2}$ isomerization reactions, only a single UV bulb was used. In addition, the direct emission from this UV-bulb was blocked, such that only photons reflected from the fixture back-reflector contributed to the light flux. The photon intensity as a function of wavelength $(300-850 \mathrm{~nm})$ was measured using a Licor (LI-1800) spectroradiometer. Using published $\mathrm{CH}_{3} \mathrm{ONO}$ cross-sections, ${ }^{10}$ and assuming a quantum yield of 1 for all wavelengths, we calculate $J_{\mathrm{CH}_{3} \mathrm{ONO}}=0.9 \times 10^{-5} \mathrm{~s}^{-1}$ $\left(J_{\mathrm{NO}_{2}}=2.8 \times 10^{-5} \mathrm{~s}^{-1}\right)$ for the measured light intensity.

$$
\mathrm{CH}_{3} \mathrm{ONO}+h v \stackrel{\mathrm{O}_{2}}{\longrightarrow} \mathrm{HO}_{2}+\mathrm{NO}+\mathrm{HCHO}
$$

$$
\mathrm{HO}_{2}+\mathrm{NO} \longrightarrow \mathrm{OH}+\mathrm{NO}_{2}
$$

High purity isoprene- $\mathrm{H}_{8}\left(\mathrm{C}_{5} \mathrm{H}_{8}\right)$ and methacrolein were purchased from Sigma-Aldrich and used without further purification. Fully deuterated isoprene (isoprene- $\mathrm{D}_{8}, \mathrm{C}_{5} \mathrm{D}_{8}$, $\frac{\mathrm{D}}{\mathrm{D}+\mathrm{H}}>0.98$, Polymer Source, Inc.) was used without purification. Gas-phase standards of $\sim 200$ ppmv of each compound were created by evaporating a known mass of liquid material into a known volume of $\mathrm{N}_{2}$. The concentration of this mixture was verified for isoprene- $\mathrm{H}_{8}$ by FTIR spectroscopy using tabulated cross-sections. ${ }^{11}$ The concentration determined from the mass and volume measurements and the IR measurements agrees to within $5 \%$. Generally, $100 \mathrm{~cm}^{3}$ of the 200 ppmv VOC mixture was transferred to the $1 \mathrm{~m}^{3}$ experiment bag using a gas-tight ground-glass syringe.

Methylnitrite $\left(\mathrm{CH}_{3} \mathrm{ONO}\right)$ was synthesized, purified, and stored using methods similar to those described by Taylor et al. ${ }^{10}$ For use in experiments, the $\mathrm{CH}_{3} \mathrm{ONO}$ trap was removed from the liquid nitrogen and allowed to warm, releasing $\sim 5 \mathrm{hPa} \mathrm{CH}_{3} \mathrm{ONO}$ vapor into an evacuated $500 \mathrm{~cm}^{3}$ bulb. The contents of the bulb were discarded. After a second fill, the bulb pressure was reduced to $\sim 0.1 \mathrm{hPa}$, and then its contents were transferred to the experiment bag.

For experiments with initial NO, a $500 \mathrm{~cm}^{3}$ bulb was filled with $\sim 15 \mathrm{hPa}$ of gas from a primary standard tank containing $1993 \pm 20$ ppmv $\mathrm{NO}$ in $\mathrm{N}_{2}$ (Matheson). The contents of the bulb are then transferred to the experiment bag.

Clean, dry air was generated from compressed house air using a FTIR purge gas generator (Perkin, Model 75-52). A known amount $(\sim 980 \mathrm{~L})$ of zero air was added to the bag using a mass flow meter (MKS).

Upon illumination, very slow photochemistry is initiated. After $\sim 4$ h of slow photochemistry, six additional unblocked UV bulbs were energized, increasing the photon flux by a factor of $\sim 30$. This rapidly completed the isoprene oxidation and allowed for mass balance to be evaluated.

Reaction products are monitored using a chemical ionization mass spectrometry (CIMS) ${ }^{12,13}$ triple quadrupole instrument. ${ }^{13,14}$ The $\mathrm{CF}_{3} \mathrm{O}^{-}$ion chemistry and instrumentation has been described in detail previously. ${ }^{12-15}$ Briefly, air is drawn from the experiment bag at a rate of $\sim 1.8$ standard litres per minute (slpm) through $\sim 1 \mathrm{~m}$ of $6.35 \mathrm{~mm}$ O.D. Teflon (PFA) tubing, where 260 standard cubic centimetres $(\mathrm{sccm})$ of gas is sub-sampled into the CIMS flowtube. The remainder of flow is routed to commercial ozone and $\mathrm{NO}_{x}$ monitors. Within the CIMS flowtube, air from the experiment bag is diluted with $1540 \mathrm{sccm}$ of dry $\mathrm{N}_{2}$ (from liquid nitrogen boiloff).

Neutral analytes react with $\mathrm{CF}_{3} \mathrm{O}^{-}$ions primarily through $\mathrm{CF}_{3} \mathrm{O}^{-}$clustering and/or fluoride transfer reactions to form product ions observed at $m / z=$ mass $_{\text {neutral }}+85 \mathrm{amu}$ and $m / z=$ mass $_{\text {neutral }}+19 \mathrm{amu}$, respectively. For certain isobaric analytes, $\mathrm{CF}_{3} \mathrm{O}^{-}$tandem $\mathrm{MS}$ analysis provides separate quantification. ${ }^{13}$ Several analytes which are undetectable using $\mathrm{CF}_{3} \mathrm{O}^{-}$ion chemistry were monitored using positive mode via $\mathrm{H}^{+} \cdot\left(\mathrm{H}_{2} \mathrm{O}\right)_{n}$ ion chemistry.

$\mathrm{H}_{2} \mathrm{O}_{2}$ was monitored using the $\mathrm{CF}_{3} \mathrm{O}^{-}$cluster ion at $m / z=119$ and quantified using calibration factors obtained from gas phase standard addition. ${ }^{12}$ Hydroperoxides, hydroxycarbonyls, and hydroxynitrates were monitored using the sum of cluster and transfer product ions, and were quantified using calculated relative ion-molecule collision rates. ${ }^{16} \uparrow \mathrm{HNO}_{3}$, $\mathrm{HONO}$, and $\mathrm{HO}_{2} \mathrm{NO}_{2}$ were monitored at transfer product ions and quantified using calibration factors obtained from standard additions. $\mathrm{H}_{2} \mathrm{O}$ concentrations were monitored using the ${ }^{13} \mathrm{CF}_{3} \mathrm{O}^{-} \cdot \mathrm{H}_{2} \mathrm{O}$ ion cluster observed at $m / z=104$, and quantified using calibration factors from standard additions of $\mathrm{H}_{2} \mathrm{O}$. Water vapor mixing ratios generally increased from 100 to 1000 ppmv over the course of the experiment from diffusion and/or leaks into the teflon bag. The sum of methylvinylketone (MVK) and methacrolein (MACR) is monitored using the positive mode product ion observed at $m / z=71$ and quantified using calibration factors from standard additions of MACR.

Experiments were performed at three different temperatures. Using a resistive heater, steady-state temperatures of 295, 310, $318 \mathrm{~K}$ were maintained. A box fan was used to circulate air within the chamber. The temperature uniformity and stability was $\pm 2 \mathrm{~K}$. 


\section{Results and discussion}

\subsection{Determination of isomerization rates}

The observations of $\mathrm{H}_{2} \mathrm{O}_{2}$, ISOPOOH, and HPALD over the first 2 hours of slow oxidation along with the recommended rate constant for $\mathrm{HO}_{2}+\mathrm{HO}_{2}$ are used to evaluate the isomerization rate for isoprene peroxy radicals relative to their reaction with $\mathrm{HO}_{2}$. In the absence of secondary chemistry, the observed time-rate-of-change for each product is equal to the production rate, defined in eqn (1)-(3).

$$
\begin{aligned}
P_{\mathrm{H}_{2} \mathrm{O}_{2}} & =k_{\mathrm{HO}_{2}+\mathrm{HO}_{2}}\left[\mathrm{HO}_{2}\right]^{2} \\
P_{\mathrm{ISOPOOH}} & =Y_{\mathrm{ISOPOOH}} k_{\mathrm{ISO}_{2}^{*}+\mathrm{HO}_{2}}\left[\mathrm{HO}_{2}\right]\left[\mathrm{ISO}_{2}^{\bullet}\right] \\
P_{\mathrm{HPALD}} & =k_{\text {isom }}\left[\mathrm{ISO}_{2}^{\bullet}\right]
\end{aligned}
$$

Here we assume $Y_{\text {ISOPOOH }}=0.88 \pm 0.12^{13}$ and use the recommended expression ${ }^{17}$ for the rate of $\mathrm{HO}_{2}$ self-reaction shown in eqn (4).

$$
\begin{aligned}
k_{\mathrm{HO}_{2}+\mathrm{HO}_{2}}= & \left\{2.2 \times 10^{-13} \exp (600 / T)\right. \\
& \left.+2.8 \times 10^{-33}[\mathrm{M}] \exp (980 / T)\right\} \\
& \times\left\{1+1.4 \times 10^{-21}\left[\mathrm{H}_{2} \mathrm{O}\right] \exp (2200 / T)\right\}
\end{aligned}
$$

Combining eqn (1)-(3),

$$
\frac{k_{\text {isom }}}{k_{\mathrm{ISO}_{2}+\mathrm{HO}_{2}}}=\frac{Y_{\mathrm{ISOPOOH}} P_{\mathrm{HPALD}}}{\left\{\frac{k_{\mathrm{HO}_{2}+\mathrm{HO}_{2}}}{P_{\mathrm{H}_{2} \mathrm{O}_{2}}}\right\}^{1 / 2} P_{\mathrm{ISOPOOH}}}
$$

The determination of $k_{\text {isom }}$ relative to $k_{\mathrm{ISO}_{2}^{\bullet}+\mathrm{HO}_{2}}$ relies only on experimental observations and the well-known $k_{\mathrm{HO}_{2}+\mathrm{HO}_{2}}$. As illustrated below, knowledge of the ratio of these rates is largely sufficient to describe the importance of this reaction in the atmosphere, as the regions where isomerization reactions become important (long ISO ${ }_{2}^{\bullet}$ lifetimes) are dominated by $\mathrm{HO}_{2}$ chemistry. Nevertheless, using the $k_{\mathrm{ISO}_{2}+\mathrm{HO}_{2}}$ recommendation from Saunders et al. ${ }^{18}$ (eqn (6)), $k_{\text {isom }}$ can be estimated.
We note that at $298 \mathrm{~K}$, this recommendation ${ }^{18}$ agrees well with the only experimental determination of this rate. ${ }^{19}$

$$
k_{\mathrm{ISO}_{2}^{*}+\mathrm{HO}_{2}}=2.06 \times 10^{-13} \exp (1300 / T)
$$

$\mathrm{OH}$ and NO levels are estimated using an explicit photochemical model. ${ }^{15}$ Observations of NO using the commercial $\mathrm{NO}_{x}$ monitor are precluded by interferences from $\mathrm{CH}_{3} \mathrm{ONO}$ and HONO. The performance of the model is evaluated through comparison with a number of observed species including $\mathrm{H}_{2} \mathrm{O}_{2}$, HPALD, ISOPOOH, MVK + MACR, ISONO $\mathrm{HONO}, \mathrm{HO}_{2} \mathrm{NO}_{2}$, and $\mathrm{HNO}_{3}$. The kinetic model reproduces the $\mathrm{H}_{2} \mathrm{O}_{2}, \mathrm{HPALD}$, ISOPOOH, MACR $+\mathrm{MVK}$, and ISONO time profiles to within $25 \%$. $\mathrm{HONO}, \mathrm{HO}_{2} \mathrm{NO}_{2}$, and $\mathrm{HNO}_{3}$ signals are small and obscured changing background levels during the slow chemistry periods of the low NO experiments. However, during the periods of increased light flux and in the high $\mathrm{NO}$ experiments the kinetic model simulations of HONO, $\mathrm{HO}_{2} \mathrm{NO}_{2}$, and $\mathrm{HNO}_{3}$ generally agree with the observations to within $30 \%$. We emphasize, however, that the determination of the 1,6-H-shift isomerization, relative to the $\mathrm{ISO}_{2}+\mathrm{HO}_{2}$ rate, does not rely on results from the kinetic model, but rather on the observed growth rates of ISOPOOH, HPALD, and $\mathrm{H}_{2} \mathrm{O}_{2}$, the assumed yields for ISOPOOH (and HPALD, $Y=1$ ), and the rate of $\mathrm{HO}_{2}$ self-reaction.

\subsection{Slow chemistry}

The very slow chemistry $\left([\mathrm{OH}] \approx 1-2 \times 10^{5} \mathrm{~mol} \mathrm{~cm}^{-3}\right.$, for experiments with no initial NO) established in these experiments enables long $\mathrm{ISO}_{2}^{\bullet}$ lifetimes, similar to those in the pristine atmosphere. ${ }^{2} \mathrm{HO}_{2}$ concentrations range from $20-40$ pptv. NO levels range from 30-60 pptv. The combined low $\mathrm{HO}_{2}$ and NO concentrations produce $\mathrm{ISO}_{2}^{\bullet}$ lifetimes of up to $\sim 50 \mathrm{~s}$. A summary of the experiments is given in Table 1 .

Fig. 1 shows time traces of $\mathrm{H}_{2} \mathrm{O}_{2}$, ISOPOOH, and HPALD

\begin{tabular}{|c|c|c|c|c|c|c|c|c|c|}
\hline Exp. VOC & $T / \mathrm{K}$ & {$[\mathrm{VOC}]_{0} / \mathrm{ppbv}$} & {$[\mathrm{NO}]_{0} / \mathrm{ppbv}$} & $\frac{\mathrm{d}\left[\mathrm{H}_{2} \mathrm{O}_{2}\right]}{\mathrm{d} t}$ & $\frac{\mathrm{d}[\mathrm{ISOPOOH}]}{\mathrm{d} t} a$ & $\frac{\mathrm{d}[\mathrm{HPALD}]}{\mathrm{d} t} b$ & $\frac{\mathrm{d}\left[\mathrm{ISONO}_{2}\right] c}{\mathrm{~d} t}$ & $\frac{\mathrm{d}[\mathrm{MVK}+\mathrm{MACR}]}{\mathrm{d} t} d$ & $\begin{array}{l}{\frac{k_{\text {isom }}}{k_{\mathrm{ISO}}+\mathrm{HO}_{2}}}^{\left(10^{8} \mathrm{~mol} \mathrm{~cm}^{-3}\right)}\end{array}$ \\
\hline 1-Isop- $\mathrm{H}_{8}$ & $295.2 \pm 1.4$ & 21.1 & 0 & $2.33 \pm 0.10$ & $4.27 \pm 0.62$ & $1.02 \pm 0.03$ & $0.53 \pm 0.02$ & $7.53 \pm 0.33$ & $1.18 \pm 0.18$ \\
\hline 2-Isop-H ${ }_{8}$ & $310.2 \pm 1.4$ & 22.6 & 0 & $3.61 \pm 0.13$ & $3.78 \pm 0.53$ & $2.78 \pm 0.08$ & $0.36 \pm 0.02$ & $5.31 \pm 0.28$ & $4.81 \pm 0.69$ \\
\hline 3-Isop-H ${ }_{8}$ & $318.2 \pm 1.4$ & 21.2 & 0 & $5.21 \pm 0.22$ & $3.10 \pm 0.31$ & $4.06 \pm 0.07$ & $0.16 \pm 0.07$ & $4.76 \pm 0.23$ & $10.7 \pm 1.1$ \\
\hline 4-Isop-H & $295.1 \pm 1.4$ & 19.0 & 19 & $0.01 \pm 0.05$ & $0.01 \pm 0.01$ & $0.35 \pm 0.12$ & $6.71 \pm 0.13$ & $50.9 \pm 0.63$ & - \\
\hline 5-Isop-D 8 & $295.3 \pm 1.4$ & 21.4 & 0 & $1.65 \pm 0.10$ & $3.81 \pm 0.41$ & $0.073 \pm 0.012$ & $0.72 \pm 0.02$ & $6.19 \pm 0.26$ & $0.08 \pm 0.02$ \\
\hline 6-Isop-D 8 & $310.2 \pm 1.4$ & 21.3 & 0 & $2.00 \pm 0.10$ & $3.26 \pm 0.41$ & $0.24 \pm 0.09$ & $0.51 \pm 0.03$ & $5.87 \pm 0.27$ & $0.36 \pm 0.06$ \\
\hline 7-Isop-D 8 & $316.8 \pm 1.4$ & 19.1 & 0 & $2.10 \pm 0.14$ & $4.04 \pm 0.75$ & $0.57 \pm 0.06$ & $0.46 \pm 0.05$ & $4.89 \pm 0.18$ & $0.71 \pm 0.16$ \\
\hline 8-Isop-D 8 & $294.9 \pm 1.4$ & 21.3 & 20 & $0.04 \pm 0.08$ & $0.02 \pm 0.03$ & $0.06 \pm 0.02$ & $5.35 \pm 0.13$ & $28.3 \pm 0.68$ & - \\
\hline
\end{tabular}
(sum of HPALD1 and HPALD2) for isoprene oxidation experiments conducted at two temperatures. The sum of ISOPOOH isomers was monitored using the $\mathrm{CF}_{3} \mathrm{O}^{-}$cluster ion observed at $m / z=203$ (isoprene- $\mathrm{H}_{8}$ ) and $m / z=211$ (isoprene- $\mathrm{D}_{8}$ ), and distinguished from the later generation

Table 1 Summary of experiments. All experiments were conducted at atmospheric pressure $(993 \pm 7 \mathrm{hPa})$. Product growth rates are given in units of pptv $\min ^{-1}$. The $1 \sigma$ precision from the linear fits are listed for product growth rates and propagated through eqn (5) to determine the $\frac{k_{\text {isom }}}{k_{\mathrm{ISO}_{2}^{*}+\mathrm{HO}_{2}}}$
precision.

${ }^{a} \mathrm{C}_{5}$-Hydroxyhydroperoxide isomers observed at $\mathrm{CF}_{3} \mathrm{O}^{-}$cluster mass of $m / z=203$ for isoprene- $\mathrm{H}_{8}$ and $m / z=211$ for isoprene- $\mathrm{D}_{8}$.

${ }^{b} \mathrm{C}_{5}$-Hydroperoxyaldehyde isomers (HPALD) attributed to form from isomerization reactions and observed at $\mathrm{CF}_{3} \mathrm{O}^{-}$-cluster mass of $m / z=$ 201 for isoprene- $\mathrm{H}_{8}$ and $m / z=208$ for isoprene- $\mathrm{D}_{8} \cdot{ }^{c} \mathrm{C}_{5}$-Hydroxynitrate isomers observed at $\mathrm{CF}_{3} \mathrm{O}^{-}$-cluster mass of $m / z=232$ for isoprene- $\mathrm{H}_{8}$ and $m / z=240$ for isoprene- $\mathrm{D}_{8}{ }^{d}$ Sum of MVK and MACR carbonyls observed at $\mathrm{H}^{+}$-cluster mass of $m / z=71$ for isoprene- $\mathrm{H}_{8}$ and $m / z=77$ for isoprene- $\mathrm{D}_{8}\left(\mathrm{MVK}-\mathrm{D}_{6}+\mathrm{MACR}_{-} \mathrm{D}_{6}\right){ }^{e}$ Bulk isomerization rate for the sum of $\mathrm{ISO}_{2}^{\bullet}$ isomers, including $\mathrm{ISO}_{2}^{\bullet}$ interconversion processes. 

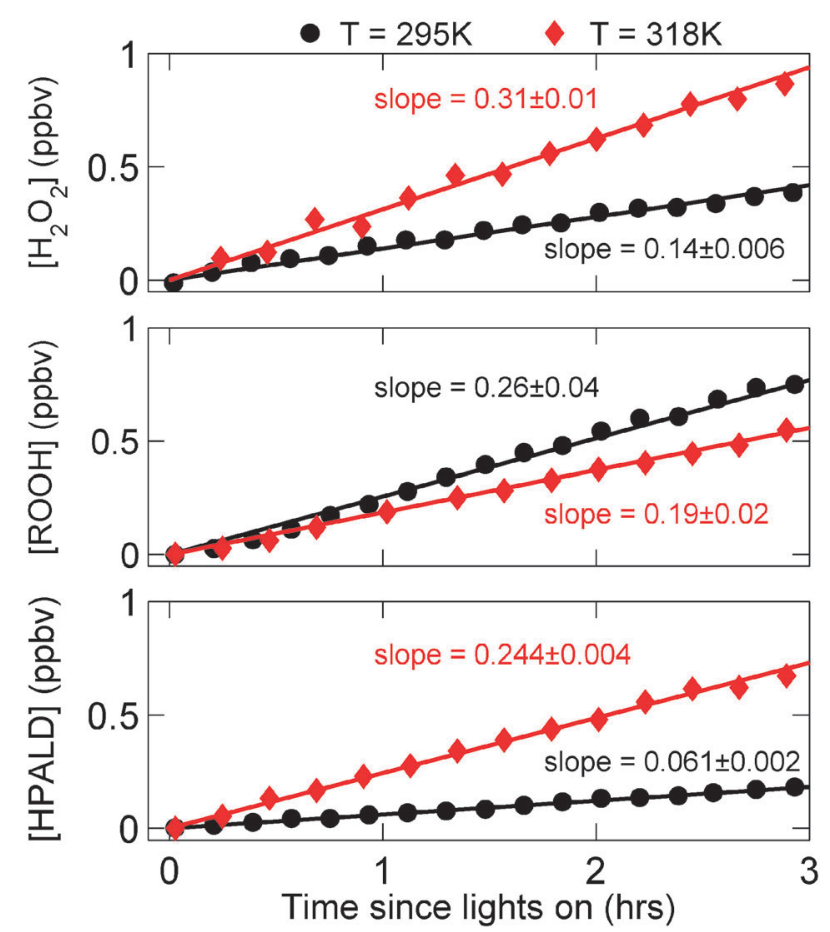

Fig. 1 Observations of $\mathrm{H}_{2} \mathrm{O}_{2}$ (top), ISOPOOH (middle), and HPALD (bottom) species during oxidation of normal isoprene $\left(\mathrm{C}_{5} \mathrm{H}_{8}\right)$. Results from experiments \#1 (circles, $T=295.2 \mathrm{~K}$ ) and \#3 (diamonds, $T=318.2 \mathrm{~K}$ ) are shown. Lines represent the best fit parameters from linear ordinary least-squares regression.

isobaric epoxide using tandem MS mode $(m / z=203 \rightarrow$ $m / z=63$ or $m / z=211 \rightarrow m / z=63) .{ }^{13}$ The sum of HPALD isomers was monitored at $m / z=201$ (isoprene- $\mathrm{H}_{8}$ ) and $m / z=208$ (isoprene- $\mathrm{D}_{8}$ ). Although HPALD compounds formed from isoprene- $\mathrm{D}_{8}$ initially contain a deuterated hydroperoxide group (-OOD) $(m / z=209)$, we observe the product at $m / z=208$. This is due to fast $\mathrm{D}-\mathrm{H}$ exchange of the hydroperoxide deuterium atom with hydrogen atoms in the background $\mathrm{H}_{2} \mathrm{O}$ on the walls of the bag and the gas sampling system. We have observed such rapid exchange in previous experiments for both hydroxy and hydroperoxy hydrogen atoms. Tandem MS investigation of both $m / z=201$ and 208 product ions gave a significant yield of the daughter ion with $m / z=63$, similar to the tandem MS of the ISOPOOH product ions, supporting the attribution of these signals to a hydroperoxide species. ${ }^{13}$

The isoprene oxidation rate is quite similar for both experiments shown in Fig. 1. The growth rate of $\mathrm{H}_{2} \mathrm{O}_{2}$ is substantially greater for the warmer experiment, however, indicating higher $\mathrm{HO}_{2}$ levels. This is consistent with enhanced $\mathrm{HO}_{2}$ production from the isomerization processes, reduced $\mathrm{HO}_{2}$ loss from $\mathrm{ISO}_{2}^{\bullet}+\mathrm{HO}_{2}$, and lower $\mathrm{NO}$ concentrations (due to the higher $\mathrm{HO}_{2}$ ).

The observed product growth rates listed in Table 1 are obtained from the slope of the ordinary least-squares fit to the CIMS observations over the first $2 \mathrm{~h}$ of photooxidation for experiments with no initial NO $(0.7 \mathrm{~h}$ for $\mathrm{NO}$ expts), along with the standard $1 \sigma$ uncertainty to the fit. In experiments with no initial $\mathrm{NO}, \sim 8 \%$ of the initial isoprene is oxidized over this period. No correction is made for the oxidation of the product species. Neglecting this loss for a product which reacts with $\mathrm{OH}$ at the same rate as isoprene produces an error of $<10 \%$

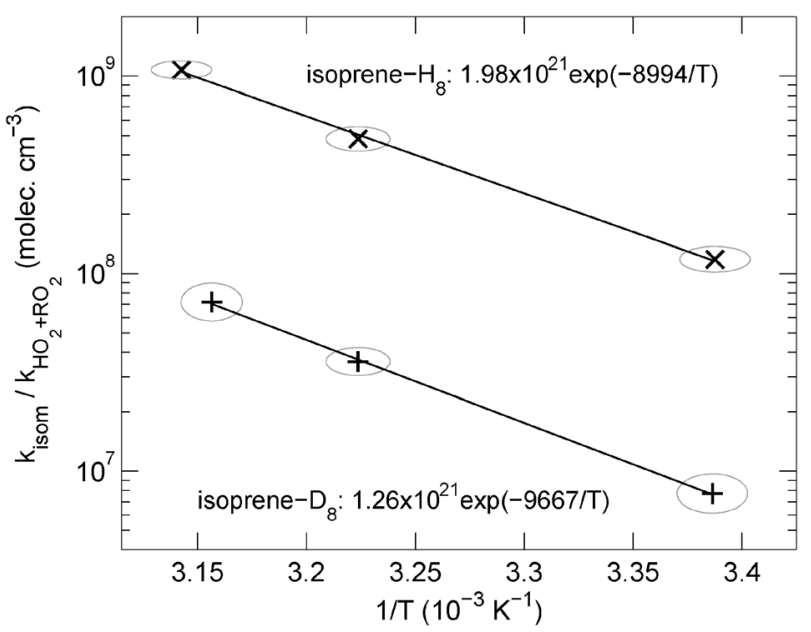

Fig. 2 Temperature dependence of 1,6- $\mathrm{H}$-shift isomerization rates yielding HPALD compounds relative to the rate of $\mathrm{ISO}_{2}^{\bullet}+\mathrm{HO}_{2}$ reaction, constrained through simultaneous observations of HPALD (HPALD1 + HPALD2), ISOPOOH, and $\mathrm{H}_{2} \mathrm{O}_{2}$ (eqn (5)) for normal $\left(\mathrm{C}_{5} \mathrm{H}_{8}, \times\right.$ symbols $)$ and deuterated $\left(\mathrm{C}_{5} \mathrm{D}_{8},+\right.$ symbols $)$ isoprene. The axes of the elipses surrounding each data point show the $1 \sigma$ uncertainty in each coordinate (Table 1).

using the method of Atkinson et al. ${ }^{20}$ For these experimental conditions, photolysis of HPALD is also negligible. Using the photolysis cross-section of MACR with a quantum yield of 1 (recommended by Peeters et $a l^{7}{ }^{7}$ ), we estimate $J_{\text {HPALD }}=2 \times 10^{-6} \mathrm{~s}^{-1}$. An explicit photochemical model of this system shows that the error in equating the observed linear increase to the average rate of production for these products over this time-frame is small $(<5 \%)$ due to the slow chemistry. In a separate experiment we have quantified the heterogeneous loss rates for HPALD, ISOPOOH, ISONO ${ }_{2}$, and $\mathrm{H}_{2} \mathrm{O}_{2}$ as $9.8 \times 10^{-6}$, $3.6 \times 10^{-6}, 3 \times 10^{-7}$, and $9.9 \times 10^{-6} \mathrm{~s}^{-1}$, respectively. Given these rates, and the timescale of the determinations $(<2 \mathrm{~h})$, heterogeneous losses do not impact the isomerization results significantly $(<3 \%)$, and as such, are neglected.

HPALD products are preferentially formed at warmer temperatures, consistent with the proposed origin involving a primary $\mathrm{H}$-shift over or through a significant barrier (Fig. 1 and Table 1). In addition, HPALD formation for isoprene- $\mathrm{D}_{8}$ is observed to be slower than for isoprene- $\mathrm{H}_{8}$ by factors of 15.4 and 13.0 at $T=295$ and $318 \mathrm{~K}$, respectively.

Fig. 2 shows the isoprene peroxy radical isomerization data listed in Table 1 on an Arrhenius plot. Also shown are the bestfit equations to the data which are derived using a York-type fit, ${ }^{21}$ accounting for uncertainties (Table 1) in both coordinates. While the observed isomerization rates are well-represented by the functional parameters shown in Fig. 2 (reproduce observations to within 5\%), these parameters are only valid for 295-318 K temperature range. Large uncertainties in these parameters and the complexity of the peroxy radical interconversion ${ }^{7}$ limit their interpretation in the traditional context of entropic and enthalpic constraints.

\subsection{Overall uncertainty in the $1,6-\mathrm{H}$-shift isomerization rate}

The uncertainty values for $\frac{k_{\text {isom }}}{k_{\mathrm{ISO}_{2}^{\circ}+\mathrm{HO}_{2}}}$ listed in Table 1 reflect only the propagated $1 \sigma$ standard precision from the ordinary 
least-square fit to the production rates of $\mathrm{H}_{2} \mathrm{O}_{2}$, ISOPOOH, and HPALD. Using the standard precision listed in Table 1 and $0.15,0.14,0.2$, and 0.4 for uncertainties in $k_{\mathrm{HO}_{2}+\mathrm{HO}_{2}}$, $Y_{\text {ISOPOOH }}, P_{\mathrm{H}_{2} \mathrm{O}_{2}}$, and in the relative calibration between ISOPOOH and HPALD, respectively, we estimate the overall uncertainty in $\frac{k_{\text {isom }}}{k_{\mathrm{ISO}_{2}^{*}+\mathrm{HO}_{2}}}$ to be $\sim 50 \%$.

\subsection{Comparison with theory}

The isomerization rate for the $1,6-\mathrm{H}$-shift for the $\delta$-isoprene peroxy radicals is substantially slower than predicted in the theoretical calculations of Peeters et al. ${ }^{7}$ and later refined in subsequent works. ${ }^{22-24}$ A direct comparison to the theoretical rate is not, however, straightforward as we only observe the end product of two important processes, namely: (a) interconversion between the $\beta-\mathrm{OH}-\mathrm{OO}, Z-\delta-\mathrm{OH}-\mathrm{OO}$, and $E-\delta-\mathrm{OH}-\mathrm{OO}$ peroxy radicals (shown for 1-OH isomers in $\mathrm{R} 9$ ); and (b) the 1,6-H-shift isomerization reactions from the two $Z-\delta-\mathrm{OH}-\mathrm{OO}$ peroxy radicals ( $\mathrm{R} 5$ and $\mathrm{R} 6)$ :

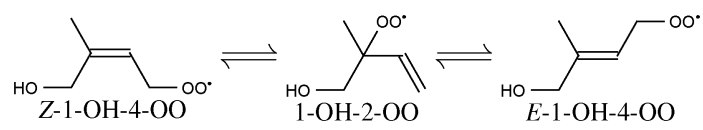

Using Peeters et al. ${ }^{7}$ estimates of $\mathrm{ISO}_{2}^{\bullet}$ interconversion rates and the refined isomerization rate for the $Z-\delta-O H-O O$ from Peeters and Muller, ${ }^{23}$ we calculate a bulk isomerization rate $\sim 50$ times faster than measured. The theoretical ratio $\frac{k_{\text {isom-H }}}{k_{\text {isom-D }}}$ from Nguyen et al. ${ }^{24}$ is a factor of $2.3(295 \mathrm{~K})$ and $1.3(318 \mathrm{~K})$ higher than experimentally observed here.

\subsection{Subsequent fate of HPALD unknown}

The maximum HPALD concentrations achieved during these experiments did not exceed 1 ppbv. The total yield was limited by the slow chemistry required for observation of the peroxy radical isomerization reactions and by the volume of the bag. Due to the low HPALD concentrations, products from its subsequent photooxidation could not be clearly identified.

\section{$2.6 \quad$ 1,5-H-shift (from alcohol)}

Peeters et $\mathrm{al}^{7}$ and da Silva et al. ${ }^{8}$ also calculated rates for 1,5-Hshift isomerization/decomposition reactions, where an alkoxy radical is formed as the alcohol hydrogen is abstracted by the peroxy group in the dominant $\beta$-hydroxyperoxy radicals formed from isoprene oxidation by $\mathrm{OH}$ (1-OH-2-OO and 4-OH-3-OO). The alkoxy radicals are expected to rapidly decompose, forming $\mathrm{OH}+\mathrm{HCHO}+\mathrm{C}_{4}$-carbonyl (MVK or MACR). Both calculations predict the same products, though with significantly different rates (Peeters et al. ${ }^{7}$ is $\sim 8 \times$ faster at $T=298 \mathrm{~K}$ ). Based on the assumption that the observed yield of MVK + MACR reported by Paulot et al. ${ }^{13}$ came from this process, the rate of Peeters $\mathrm{et} \mathrm{al.}{ }^{7}$ was adjusted upwards by a factor of 5 in the more recent study of Peeters and Muller. ${ }^{23}$ Paulot et al., ${ }^{13}$ however, attributed the observed MVK + MACR yield $([12 \pm 12] \%)$ to a radical channel in the $\mathrm{ISO}_{2}^{\bullet}+\mathrm{HO}_{2}$ reaction. In addition, uncertainties in the $\mathrm{ISO}_{2}^{\bullet}+\mathrm{ISO}_{2}^{\bullet}$ reaction rates as well as in the determination of the fraction of $\mathrm{ISO}_{2}^{\bullet}$ radicals reacting with $\mathrm{NO}$ could very well account for all the observed MVK + MACR reported in the Paulot et al. study. ${ }^{13}$
We are unable to experimentally estimate the rate of the 1,5-H-shift in this study primarily due to large uncertainties in the $\mathrm{ISO}_{2}^{\bullet}+\mathrm{ISO}_{2}^{\bullet}$ reaction rate constants and product branching ratios, as well as uncertainties in the $\mathrm{ISO}_{2}^{-}$-isomer specific nitrate yields from $\mathrm{ISO}_{2}^{\bullet}+\mathrm{NO}$, and unknown temperature dependencies for all these parameters. Using the $\mathrm{ISO}_{2}^{\bullet}+\mathrm{ISO}_{2}^{\bullet}$ parameters recommended by Jenkin et al., ${ }^{25}$ and the nitrate yields of Paulot et al. ${ }^{15}$ coupled with the temperature dependence recommended by Carter and Atkinson, ${ }^{26}$ the observed isoprene-nitrate/(MVK + MACR) ratio is not, however, compatible with the 1,5-H-shift rate recommended by Peeters and Muller. ${ }^{23}$ The rate calculated by da Silva et al. ${ }^{8}$ (a factor of $\sim 40$ slower) is consistent with our observations, but also not well-constrained (ESI $\dagger$, Fig. S1). In any case, this isomerization channel is likely only of minor importance in the atmosphere.

\subsection{Nitrate yields and ISO$_{2}^{\bullet}$ interconversion}

Isoprene nitrate yields are observed to decrease relative to MVK + MACR with increasing temperature. This is consistent with previous studies of the temperature dependence of organic nitrate formation (e.g., Carter and Atkinson ${ }^{26}$ ) and is attributed to a longer lifetime of the excited ROONO* (and/or $\mathrm{RONO}_{2}{ }^{*}$ ) complex at cooler temperatures allowing for increased collisional deactivation. ${ }^{27}$ Similarly, we attribute the much higher isoprene- $\mathrm{D}_{8}$ hydroxy nitrate yields relative to those from isoprene- $\mathrm{H}_{8}$ (a factor of 1.7 and 1.4 for low and high $\mathrm{NO}$ conditions, expts 1,5 and 4,8 , Table 1) to increased stabilization of the ROONO* (and/or $\mathrm{RONO}_{2}{ }^{*}$ ) complex from nearby deuterium atoms as compared with hydrogen atoms.

There is a significant difference in the ratio of $\mathrm{ISONO}_{2} /$ (MVK + MACR) between the high and low NO experiments at $295 \mathrm{~K}$. While this difference could result from more heterogeneous nitrate loss in the slow experiment, it may reflect differences in the peroxy radical distribution between these two experiments as the high NO experiment would be closer to the initial kinetic distribution of $\mathrm{ISO}_{2}^{\bullet}$ (higher fraction in $\delta$ ) and the slow experiment closer to the thermodynamic equilibrium for $\mathrm{ISO}_{2}^{\bullet}$ (lower fraction in $\delta$ ). ${ }^{7}$ Giacopelli et al. ${ }^{28}$ and Paulot et al. ${ }^{15}$ estimate significantly higher nitrate yields from the $\delta$-hydroxy peroxy radicals as compared to the $\beta$-hydroxy peroxy radicals. The isomer-specific nitrate yields reported by Lockwood et al., ${ }^{29}$ however, are somewhat different than those reported by Giacopelli et al. ${ }^{28}$ and inferred by Paulot et al. ${ }^{15}$ The reasons for these differences are not currently understood.

The large (up to $\sim 30 \%$ ), and continued increase in HPALD yields with temperature provides evidence that the isoprene peroxy radicals do indeed interconvert on the timescale of the estimated lifetime of the peroxy radicals in these experiments $(\sim 50 \mathrm{~s})$.

\section{Atmospheric implications}

The fraction of isoprene peroxy radicals undergoing isomerization in Earth's atmosphere was estimated using the GEOS-Chem (v8.3.2) 3-D global model ${ }^{30}$ with a modified chemical mechanism including updated isoprene chemistry as described previously. ${ }^{13,15,31}$ Simulations were conducted with and without 


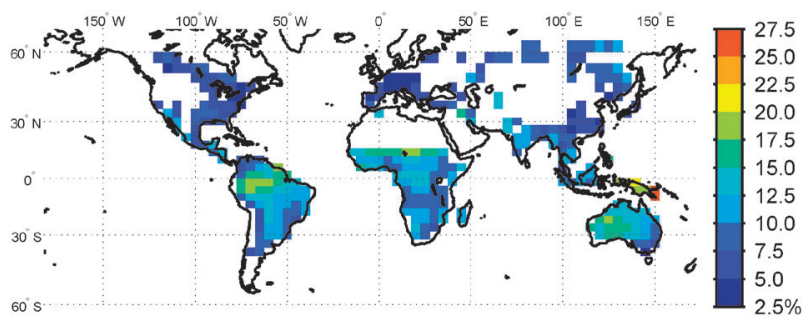

Fig. 3 Annual boundary layer $(P>800 \mathrm{hPa})$ percentage of isoprene peroxy radicals undergoing isomerization simulated using the GEOS-Chem chemical transport model at a resolution of $4^{\circ}$ lat. $\times 5^{\circ}$ long. Regions where isoprene mean monthly emissions are $<1 \times 10^{11} \mathrm{~mol} \mathrm{~cm}^{-2} \mathrm{~s}^{-1}$ are excluded. Data from simulations using $\frac{k_{\text {isom }}-\mathrm{H}_{8}}{k_{\mathrm{ISO}_{2}+\mathrm{HO}_{2}}}$ given in Fig. 2 and $k_{\mathrm{ISO}_{2}+\mathrm{HO}_{2}}$ from Saunders et al. ${ }^{18}$ (eqn (6)).

the isoprene peroxy radical isomerization for the June 2006-May 2007 time period with a 1.5 year model spin-up. We implemented the isomerization process through the addition of R10. Due to uncertainties regarding the fate of HPALD we did not consider the further oxidation chemistry of this compound. This is equivalent to considering the subsequent chemistry as $\mathrm{HO}_{x}$-neutral. In addition, the sensitivity of the model to the rate coefficient for the reaction of isoprene peroxy radicals with $\mathrm{HO}_{2}$ was investigated. In the standard GEOS-Chem mechanism, the rate of $\mathrm{ISO}_{2}^{\bullet}+\mathrm{HO}_{2}$ is $k_{\mathrm{ISO}_{2}^{*}+\mathrm{HO}_{2}}=7.40 \times 10^{-13} \exp (700 / T)$. At $T=298 \mathrm{~K}$, this rate is $\sim \frac{1}{2}$ that calculated from eqn (6). While this does not change the ratio of $k_{\text {isom }}$ relative to $k_{\mathrm{ISO}_{2}^{\bullet}+\mathrm{HO}_{2}}$ (as we determined only the relative value), it does reduce both rates relative to $k_{\mathrm{ISO}_{2}^{*}+\mathrm{NO}}$.

$$
\mathrm{ISO}_{2}^{\bullet} \stackrel{k_{\text {isom }}}{\longrightarrow} \mathrm{HO}_{2}
$$

Isoprene peroxy radicals are predicted to react $44.1 \%$ with $\mathrm{NO}, 42.6 \%$ with $\mathrm{HO}_{2}$, with $7.4 \%$ isomerizing to form HPALD using the slow $\mathrm{ISO}_{2}^{\bullet}+\mathrm{HO}_{2}$ rate. Simulations using the faster $\mathrm{ISO}_{2}^{\circ}+\mathrm{HO}_{2}$ rate (eqn (6)) result in the following isoprene $\mathrm{ISO}_{2}^{\circ}$ loss distribution: $33.5 \%$ reaction with $\mathrm{NO}, 53.5 \%$ reaction with $\mathrm{HO}_{2}$, and $9.6 \%$ isomerization. As expected, the ratio between the $\mathrm{HO}_{2}$ /isomerization loss processes remains about the same in these two simulations. The spatial distribution of the fraction of isoprene peroxy radicals predicted to undergo isomerization reaction is shown in Fig. 3. While not the dominant process suggested previously, ${ }^{7,22,23,32}$ peroxy radical isomerization is an important process for isoprene oxidation in the atmosphere even at the slow rate reported here. HPALD oxidation pathway(s), the resulting product(s), and the oxidation thereof remain unknown. These pathways, along with uncertainties in the relative rates of $\mathrm{ISO}_{2}^{\bullet}+\mathrm{HO}_{2}$ and $\mathrm{ISO}_{2}^{\bullet}+\mathrm{NO}$, contribute substantially to the overall uncertainty in the atmospheric oxidation of isoprene, and hence, are deserving of further study.

In a series of manuscripts, ${ }^{33-38}$ Jorand, Perrin, Blin-Simiand and co-workers have reported peroxy radical isomerizations in several systems at elevated temperatures. They have suggested that such isomerization reactions may be important for atmospheric chemistry. Until now, however, such mechanisms have not been studied under conditions relevant for atmospheric chemistry, nor have they been incorporated into the mechanisms of atmospheric chemistry models. In this work, we provide experimental evidence for the importance of such peroxy radical isomerization reactions under atmospherically relevant conditions. From the isomerization rates determined here, isoprene peroxy radical isomerization reactions are unlikely to reconcile the differences in $\mathrm{HO}_{x}$ levels between observations and model simulations. ${ }^{32}$ It is possible, however, that other similar isomerization reactions contribute to $\mathrm{HO}_{x}$ reformation. For example, similar studies on the oxidation of MACR performed in our laboratory (Crounse et al., in preparation) provide evidence for a fast $1,4-\mathrm{H}$-shift isomerization from the peroxy radical formed after $\mathrm{OH}$ addition to the external olefinic carbon, yielding $\mathrm{OH}$ and hydroxyacetone. Previous theoretical calculations have also demonstrated the feasibility of such 1,4-H-shift isomerizations in similar systems. ${ }^{39-41}$ It is likely that such processes occur in the gas phase oxidation of other organic compounds for conditions where $\mathrm{RO}_{2}$ lifetimes become sufficiently long. The methods described in this work should be generally useful for the future investigation of $\mathrm{RO}_{2}$ isomerization reactions under atmospherically relevant conditions.

\section{Acknowledgements}

We thank N. C. Eddingsaas for the design and construction of the mini-chamber used in this work, M. R. Beaver for assistance with experiments, J. M. St. Clair for instrumental assistance, K. M. Spencer for providing CIMS calibrations of glycolaldehyde and hydroxyacetone, and D. L. Thomsen and H. C. Knap for assistance with theoretical calulations. We thank NASA (NNX08AD29G) and NSF (ATM-0934408) for funding in support of this work. We thank the Danish Council for Independent Research-Natural Sciences and the Danish Center for Scientific Computing (DCSC) for funding. FP acknowledges support from NASA earth and space science fellowship.

\section{References}

1 A. Guenther, T. Karl, P. Harley, C. Wiedinmyer, P. I. Palmer and C. Geron, Atmos. Chem. Phys., 2006, 6, 3181-3210.

2 J. Lelieveld, T. M. Butler, J. N. Crowley, T. J. Dillon, H. Fischer, L. Ganzeveld, H. Harder, M. G. Lawrence, M. Martinez, D. Taraborrelli and J. Williams, Nature, 2008, 452, 737-740.

3 D. Tan, I. Faloona, J. B. Simpas, W. Brune, P. B. Shepson, T. L. Couch, A. L. Sumner, M. A. Carroll, T. Thornberry, E. Apel, D. Riemer and W. Stockwell, J. Geophys. Res., 2001, 106, 24407-24427.

4 J. A. Thornton, P. J. Wooldridge, R. C. Cohen, M. Martinez, H. Harder, W. H. Brune, E. J. Williams, J. M. Roberts, F. C. Fehsenfeld, S. R. Hall, R. E. Shetter, B. P. Wert and A. Fried, J. Geophys. Res., 2002, 107 (D12), 4146, DOI: 10.1029/ 2001JD000932.

5 X. Ren, J. R. Olson, J. H. Crawford, W. H. Brune, J. Mao, R. B. Long, Z. Chen, G. Chen, M. A. Avery, G. W. Sachse, J. D. Barrick, G. S. Diskin, L. G. Huey, A. Fried, R. C. Cohen, B. Heikes, P. O. Wennberg, H. B. Singh, D. R. Blake and R. E. Shetter, J. Geophys. Res., 2008, 113, D05310, DOI: 10.1029/2007JD009166.

6 A. Hofzumahaus, F. Rohrer, K. Lu, B. Bohn, T. Brauers, C.-C. Chang, H. Fuchs, F. Holland, K. Kita, Y. Kondo, X. Li, S. Lou, M. Shao, L. Zeng, A. Wahner and Y. Zhang, Science, 2009, 324, 1702-1704.

7 J. Peeters, T. L. Nguyen and L. Vereecken, Phys. Chem. Chem. Phys., 2009, 11, 5935-5939.

8 G. da Silva, C. Graham and Z.-F. Wang, Environ. Sci. Technol., 2010, 44, 250-256. 
9 R. A. Cox, R. G. Derwent, S. V. Kearsey, L. Batt and K. G. Patrick, J. Photochem., 1980, 13, 149-163.

10 W. D. Taylor, T. D. Allston, M. J. Moscato, G. B. Fazekas, R. Kozlowski and G. A. Takacs, Int. J. Chem. Kinet., 1980, 12, 231-240.

11 S. W. Sharpe, T. J. Johnson, R. L. Sams, P. M. Chu, G. C. Rhoderick and P. A. Johnson, Appl. Spectrosc., 2004, 58, $1452-1461$.

12 J. D. Crounse, K. A. McKinney, A. J. Kwan and P. O. Wennberg, Anal. Chem., 2006, 78, 6726-6732.

13 F. Paulot, J. D. Crounse, H. G. Kjaergaard, A. Kuerten, J. M. St. Clair, J. H. Seinfeld and P. O. Wennberg, Science, 2009, 325, 730-733.

14 J. M. St. Clair, D. C. McCabe, J. D. Crounse, U. Steiner and P. O. Wennberg, Rev. Sci. Instrum., 2010, 81, 094102.

15 F. Paulot, J. D. Crounse, H. G. Kjaergaard, J. H. Kroll, J. H. Seinfeld and P. O. Wennberg, Atmos. Chem. Phys., 2009, 9, 1479-1501.

16 A. L. Garden, F. Paulot, J. D. Crounse, I. J. Maxwell-Cameron, P. O. Wennberg and H. G. Kjaergaard, Chem. Phys. Lett., 2009, 474, 45-50.

17 R. Atkinson, D. L. Baulch, R. A. Cox, J. N. Crowley, R. F. Hampson, R. G. Hynes, M. E. Jenkin, M. J. Rossi and J. Troe, Atmos. Chem. Phys., 2004, 4, 1461-1738.

18 S. M. Saunders, M. E. Jenkin, R. G. Derwent and M. J. Pilling, Atmos. Chem. Phys., 2003, 3, 161-180.

19 A. A. Boyd, P. M. Flaud, N. Daugey and R. Lesclaux, J. Phys Chem. A, 2003, 107, 818-821.

20 R. Atkinson, S. M. Aschmann, W. P. L. Carter, A. M. Winer and J. N. Pitts, J. Phys. Chem., 1982, 86, 4563-4569.

21 D. York, N. M. Evensen, M. L. Martinez and J. D. Delgado, Am. J. Phys., 2004, 72, 367-375.

22 T. Stavrakou, J. Peeters and J. F. Muller, Atmos. Chem. Phys., 2010, 10, 9863-9878.

23 J. Peeters and J.-F. Muller, Phys. Chem. Chem. Phys., 2010, 12, $14227-14235$.

24 T. L. Nguyen, L. Vereecken and J. Peeters, ChemPhysChem, 2010, 11, 3996-4001.
25 M. E. Jenkin, A. A. Boyd and R. Lesclaux, J. Atmos. Chem., 1998, 29, 267-298.

26 W. P. L. Carter and R. Atkinson, J. Atmos. Chem., 1989, 8, 165-173.

27 J. R. Barker, L. L. Lohr, R. M. Shroll and S. Reading, J. Phys. Chem. A, 2003, 107, 7434-7444.

28 P. Giacopelli, K. Ford, C. Espada and P. B. Shepson, J. Geophys. Res., 2005, 110, D01304, DOI: 10.1029/2004JD005123.

29 A. L. Lockwood, P. B. Shepson, M. N. Fiddler and M. Alaghmand, Atmos. Chem. Phys., 2010, 10, 6169-6178.

30 I. Bey, D. J. Jacob, R. M. Yantosca, J. A. Logan, B. D. Field, A. M. Fiore, Q. B. Li, H. G. Y. Liu, L. J. Mickley and M. G. Schultz, J. Geophys. Res., 2001, 106, 23073-23095.

31 F. Paulot, D. Wunch, J. D. Crounse, G. C. Toon, D. B. Millet, P. F. DeCarlo, C. Vigouroux, N. M. Deutscher, G. González Abad, J. Notholt, T. Warneke, J. W. Hannigan, C. Warneke, J. A. de Gouw, E. J. Dunlea, M. De Mazière, D. W. T. Griffith, P. Bernath, J. L. Jimenez and P. O. Wennberg, Atmos. Chem. Phys., 2011, 11, 1989-2013.

32 A. T. Archibald, M. C. Cooke, S. R. Utembe, D. E. Shallcross, R. G. Derwent and M. E. Jenkin, Atmos. Chem. Phys., 2010, 10, 8097-8118.

33 O. Perrin, A. Heiss, K. Sahetchian, L. Kerhoas and J. Einhorn, Int. J. Chem. Kinet., 1998, 30, 875-887.

34 O. Perrin, A. Heiss, F. Doumenc and K. Sahetchian, J. Chem. Soc., Faraday Trans., 1998, 94, 2323-2335.

35 F. Jorand, A. Heiss, K. Sahetchian, L. Kerhoas and J. Einhorn, J. Chem. Soc., Faraday Trans., 1996, 92, 4167-4171.

36 F. Jorand, A. Heiss, O. Perrin, K. Sahetchian, L. Kerhoas and J. Einhorn, Int. J. Chem. Kinet., 2003, 35, 354-366.

37 N. Blin-Simiand, F. Jorand, K. Keller, M. Fiderer and K. Sahetchian, Combust. Flame, 1998, 112, 278-282.

38 N. Blin-Simiand, F. Jorand, K. Sahetchian, M. Brun, L. Kerhoas, C. Malosse and J. Einhorn, Combust. Flame, 2001, 126, 1524-1532.

39 K. T. Kuwata, K. L. Ternpleton and A. S. Hasson, J. Phys. Chem. A, 2003, 107, 11525-11532.

40 G. da Silva, Phys. Chem. Chem. Phys., 2010, 12, 6698-6705.

41 R. Asatryan, G. da Silva and J. W. Bozzelli, J. Phys. Chem. A, 2010, 114, 8302-8311. 